\title{
Evaluation of Clinical Drug Interaction Potential of Clofazimine Using Static and Dynamic Modeling Approaches ${ }^{\mathbb{S}}$
}

\author{
Ramachandra Sangana, Helen Gu, Dung Yu Chun, ${ }^{1}$ and Heidi J. Einolf \\ Novartis Healthcare Pvt. Ltd., Hyderabad, India (R.S.); and Novartis Institutes for Biomedical Research, East Hanover, New Jersey \\ (H.G., D.Y.C., H.J.E.) \\ Received July 28, 2017; accepted October 12, 2017
}

\section{ABSTRACT}

The 2016 World Health Organization treatment recommendations for drug-resistant tuberculosis (DR-TB) positioned clofazimine as a core second-line drug. Being identified as a cytochrome P450 (P450) inhibitor in vitro, a P450-mediated drug interaction may be likely when clofazimine is coadministered with substrates of these enzymes. The P450-mediated drug interaction potential of clofazimine was evaluated using both static [estimation of the $\boldsymbol{R}_{\mathbf{1}}$ and area under the plasma concentration-time curve ratio (AUCR) values] and dynamic [physiologically based pharmacokinetics (PBPK)] modeling approaches. For static and dynamic predictions, midazolam, repaglinide, and desipramine were used as probe substrates for CYP3A4/5, CYP2C8, and CYP2D6, respectively. The AUCR static model estimations for clofazimine with the substrates midazolam,

repaglinide, and desipramine were $5.59,1.34$, and 1.69 , respectively. The fold increases in the area under the curve (AUC) predicted for midazolam, repaglinide, and desipramine with clofazimine (based on PBPK modeling) were 2.69, 1.60, and 1.47, respectively. Clofazimine was predicted to be a moderate-to-strong CYP3A4/5 inhibitor and weak CYP2C8 and CYP2D6 inhibitor based on the calculated AUCR by static and PBPK modeling. Additionally, for selected antiretroviral, antitubercular, antihypertensive, antidiabetic, antileprotics, and antihyperlipidemic CYP3A4/5 substrate drugs, approximately 2- to 6-fold increases in the AUC were predicted with static modeling when coadministered with $100 \mathrm{mg}$ of clofazimine. Therefore, the possibility of an increase in the AUC of CYP3A4/5 substrates when coadministered with clofazimine cannot be ignored.

\section{Introduction}

Tuberculosis (TB) is an airborne infectious disease caused by organisms of the Mycobacterium tuberculosis complex. Over the past two decades, the incidence of TB has declined in most regions of the world; however, the emergence of resistance to anti-TB drugs is a threat to the gains in TB control. Drug-resistant TB (DR-TB) cases are generally of three types: 1) rifampicin-resistant $\mathrm{TB}$, caused by bacteria that do not respond to rifampicin; 2) multidrug-resistant TB (MDR-TB), caused by bacteria that do not respond to, at least, isoniazid and rifampicin; and 3) extensively drug-resistant TB, a form of MDR-TB that is also resistant to fluoroquinolones and second-line injectable drugs [see the World Health Organization (WHO) MDR-TB factsheet; http:// www.who.int/tb/areas-of-work/drug-resistant-tb/treatment/en/].

Clofazimine is an antimycobacterial agent originally developed in the 1950s for TB and currently approved for the treatment of lepromatous leprosy and its complication, erythema nodosum leprosum (Fajardo et al., 1999; Hwang et al., 2014). Clofazimine has been used off-label as

${ }^{1}$ Current affiliation: Insmed Inc., Bridgewater, New Jersey.

The funding for writing assistance was provided by Novartis Pharma AG, Basel, Switzerland.

https://doi.org/10.1124/dmd.117.077834

SThis article has supplemental material available at dmd.aspetjournals.org. a second-line TB drug in a multidrug regimen for DR-TB (see the companion handbook to the WHO guidelines for the programmatic management of drug-resistant tuberculosis; https://www.ncbi.nlm.nih.gov/ books/NBK247431). Publication of various drug regimens used by the Damien Foundation in Bangladesh (Van Deun et al., 2010), which included clofazimine as part of the treatment protocol, has drawn the attention of researchers, and authors have continued to study clofazimine as part of a multidrug regimen in the treatment of MDR-TB (Dooley et al., 2013). Among the five different regimens used in Bangladesh, the regimen containing clofazimine for MDR-TB had a low failure rate and a treatment default rate of $7.9 \%$ without any relapses up to 2 years in cured patients (Van Deun et al., 2010). In the follow-up study, $84.4 \%$ of patients had bacteriologically favorable treatment outcomes after 2 years (Aung et al., 2014). A similar outcome has been reported from countries in Africa (Piubello et al., 2014; Kuaban et al., 2015). The 2016 WHO DR-TB treatment guidelines positioned clofazimine as a core second-line drug (group C) (http://www.who.int/tb/areas-of-work/drug-resistant-tb/treatment/en/).

In 2015, an estimated 10.4 million new (incident) TB cases were reported worldwide, and among these, 1.2 million (11\%) cases had been living with human immunodeficiency virus (HIV). In addition to the 1.4 million TB deaths in 2015, 0.4 million deaths were reported among people living with HIV (see the WHO global tuberculosis report; www.who.int/tb/publications/global_report/en/). TB is one of the most

ABBREVIATIONS: AUC, area under the curve; AUCR, area under the curve ratio; DDI, drug-drug interaction; DR-TB, drug-resistant tuberculosis; $f_{\mathrm{a}}$, fraction absorbed; $F_{\mathrm{g}}$, fraction of dose that escapes first-pass elimination in the intestine; $f_{\mathrm{m}}$, fraction metabolized by an enzyme; fu , fraction unbound in plasma; HIV, human immunodeficiency virus; [ $\left.\mathrm{I}_{\text {gut }}\right]$, gut concentration; $k_{\mathrm{a}}$, first-order absorption rate constant in vivo; $K_{\mathrm{i}, \mathrm{u}}$, unbound inhibition constant; MDR-TB, multidrug-resistant tuberculosis; P450, cytochrome P450; PBPK, physiologically based pharmacokinetics; PK, pharmacokinetics; PopPK, population pharmacokinetics, TB, tuberculosis; WHO, World Health Organization. 
common opportunistic infections and a leading cause of death in HIV patients (www.who.int/tb/publications/global_report/en/). The augmented reports of MDR-TB and synergistic interactions with the HIV epidemic are posing difficult challenges for effective management and control of TB (Zumla et al., 2013).

Clofazimine is always prescribed as part of a multidrug regimen for the treatment of DR-TB. Given that TB contributes to comorbidity in patients with HIV, concomitant administration of anti-HIV drugs with clofazimine is most likely. In vitro cytochrome P450 (P450) inhibition results (Supplemental Table 1) have suggested that clofazimine has reversible inhibitory effects on CYP3A4/5, CYP2C8, and CYP2D6 at concentrations of up to $10 \mu \mathrm{M}$. Therefore, it becomes imperative to evaluate the drug interaction potential of clofazimine with drugs that are substrates for CYP3A4/5, CYP2C9, and CYP2D6. This study evaluated the CYP3A4/5, CYP2C8, and CYP2D6 inhibition-mediated drug interaction potential of clofazimine (as a perpetrator) using static and dynamic [i.e., physiologically based pharmacokinetics (PBPK)] models.

\section{Materials and Methods}

The drug interaction potential of clofazimine (P450 mediated) was evaluated using static and mechanistic dynamic model predictions according to the Food and Drug Administration Guidance for Industry for drug interaction studies (https://www.fda.gov/downloads/drugs/guidances/ucm292362.pdf).

\section{Static Model Predictions}

P450 inhibition parameters were collected from data obtained using pooled human liver microsomes, which indicated that clofazimine reversibly inhibits CYP3A4/5, CYP2C8, and CYP2D6 with unbound dissociation constant values of $0.000786,0.00372$, and $0.00246 \mu \mathrm{M}$, respectively (see Supplemental Table 1). The human plasma protein binding of clofazimine was reported as $99.9 \%$, ranging from 99.9\% to $99.96 \%$ (see the TB Alliance report on clofazimine in clinical trials for tuberculosis; http://www.resisttb.org/wp-content/uploads/2013/08/Global-AllianceClinical-Work-with-Clofazimine.pdf). Therefore, a correction for plasma protein binding of $99.9 \%$ [fraction unbound in plasma $\left(\mathrm{fu}_{\mathrm{p}}\right)$ of 0.001 ] was used for all calculations in this analysis. Although there is one report of potential weak ( $\leq 2$-fold) CYP3A4 activity induction in vitro (Horita and Doi, 2014), there are no published reports that have implicated clofazimine as a clinical inducer of CYP3A4 (see the University of Washington Drug Interaction Database; https://didb.druginteractioninfo. org). Therefore, it was assumed in the models that any potential CYP3A4 induction would be negligible, and for the worst-case scenario CYP3A4 inhibition would predominate. A population pharmacokinetics (PopPK) model was developed for clofazimine using plasma concentration-time data obtained from healthy volunteers and leprosy patients (internal data). Simulations were performed using the PopPK parameter estimates obtained from the final model. A steady-state plasma $C_{\max }$ value of $890 \mathrm{ng} / \mathrm{ml}(1.89 \mu \mathrm{M})$ (after repeat dose administration of $100 \mathrm{mg}$ once daily) was obtained from the model, which was used for the $R_{1}$ and area under the curve (AUC) plasma concentration-time ratio (AUCR) calculations.

Determination of the $\boldsymbol{R}_{\mathbf{1}}$ Value. The $R_{1}$ value was calculated using the following formula:

$$
R_{1}=1+[\mathrm{I}] / K_{\mathrm{i}, \mathrm{u}}
$$

where [I] is the maximum anticipated $C_{\max }$ of clofazimine in patients $[1.89 \mu \mathrm{M}$ (total $C_{\max }$ ) or $0.00189 \mu \mathrm{M}$ (unbound $C_{\max }$ )] and $K_{\mathrm{i}, \mathrm{u}}$ is the unbound inhibition constant determined in vitro. The $K_{\mathrm{i}, \mathrm{u}}$ values used in the models for $\mathrm{P} 450$ inhibition were $0.00372 \mu \mathrm{M}$ (CYP2C8), $0.00246 \mu \mathrm{M}$ (CYP2D6), and 0.000786 $\mu \mathrm{M}(\mathrm{CYP} 3 \mathrm{~A} 4 / 5)$, vide supra.

Since clofazimine is a CYP3A4/5 inhibitor that will be administered orally, the $R_{1}$ value was also determined using the gut concentration $\left[\mathrm{I}_{\text {gut }}\right]$, to take into account intestinal CYP3A inhibition

$$
R_{1}=1+\left[\mathrm{I}_{\text {gut }}\right] / K_{\mathrm{i}, \mathrm{u}}
$$

where $\left[\mathrm{I}_{\text {gut }}\right]=$ dose $/ 250 \mathrm{ml}$ (or $845 \mu \mathrm{M}$ for $100 \mathrm{mg}$ dose). Initially, the $R_{1}$ value for P450 (CYP3A4/5, CYP2C8, and CYP2D6) inhibition by clofazimine was calculated; if the $R_{1}$ values were $>1.1$ (systemic) or $>11$ (gut; only for CYP3A4/5), then the AUCR and $\mathrm{AUC}_{\text {inhibitor }} / \mathrm{AUC}_{\text {control }}$ were estimated using the mechanistic static (net effect) model.

Determination of the AUCR Value by Using the Mechanistic Static (Net Effect) Model. The net effect model was used to calculate the AUCR (Fahmi et al., 2008, 2009; Einolf et al., 2014). The AUCR value was calculated using the following formula:

$$
\begin{aligned}
& \mathrm{AUCR}=\left[\frac{1}{\left(A_{\mathrm{g}} \times B_{\mathrm{g}} \times C_{\mathrm{g}}\right) \times\left(1-F_{\mathrm{g}}\right)+F_{\mathrm{g}}}\right] \\
& \times\left[\begin{array}{c}
1 \\
\hline\left(\begin{array}{llllll}
A_{\mathrm{h}} & \times & B_{\mathrm{h}} & \times & \left.C_{\mathrm{h}}\right) \times f_{\mathrm{m}}+\left(1-f_{\mathrm{mP} 450}\right.
\end{array}\right]
\end{array}\right.
\end{aligned}
$$

where $F_{\mathrm{g}}$ is the fraction of dose that escapes first-pass metabolism in the intestine; $f_{\mathrm{mP} 450}$ is the fraction of total systemic clearance of the substrate that is metabolized by an individual P450 enzyme; and subscripts "h" and "g" denote liver and gut, respectively.

Since clofazimine exhibits reversible inhibition but not time-dependent inactivation or clinically relevant induction

$$
\begin{aligned}
& A_{\mathrm{g}}=1 /\left(1+\left[\mathrm{I}_{\text {ent }}\right]\right) / K_{\mathrm{i}} \\
& A_{\mathrm{h}}=1 /\left(1+\left[\mathrm{I}_{\mathrm{h}}\right]\right) / K_{\mathrm{i}}
\end{aligned}
$$

and $B_{\mathrm{g}}, C_{\mathrm{g}}, B_{\mathrm{h}}$, and $C_{\mathrm{h}}$ were set as 1 .

In eq. $4,\left[\mathrm{I}_{\mathrm{ent}}\right]$ is the enterocyte concentration of clofazimine defined as follows:

$$
\left[\mathrm{I}_{\mathrm{ent}}\right]=f_{\mathrm{a}} \times k_{\mathrm{a}} \times \operatorname{dose} / Q_{\mathrm{ent}}
$$

where $f_{\mathrm{a}}$ is the fraction of clofazimine absorbed after oral administration (0.7) (Vischer, 1969); $k_{\mathrm{a}}$ is the first-order absorption rate constant in vivo (0.088 hour ${ }^{-1}$, internal data); and $Q_{\text {ent }}$ is the enterocytic blood flow ( $248 \mathrm{ml} / \mathrm{min}$ ) (Obach et al., 2006).

In eq. $5,\left[I_{h}\right]$ is the hepatic concentration of clofazimine defined as follows:

$$
\left[\mathrm{I}_{\mathrm{h}}\right]=\mathrm{fu}_{\mathrm{p}} \times\left[C_{\max , \text { total }}+\left(k_{\mathrm{a}} \times f_{\mathrm{a}} \times \operatorname{dose} / Q_{\mathrm{h}}\right)\right]
$$

where $Q_{\mathrm{h}}$ is the hepatic blood flow [1470 $\mathrm{ml} / \mathrm{min}$ for a $70-\mathrm{kg}$ individual $(21 \mathrm{ml} / \mathrm{min}$ per kilogram)] and $\mathrm{fu}_{\mathrm{p}}$ is the fraction unbound in plasma (0.001) (http://www. resisttb.org/wp-content/uploads/2013/08/Global-Alliance-Clinical-Workwith-Clofazimine.pdf). The dose was defined as $100 \mathrm{mg}$ and the $C_{\max }$ total value (at steady state) was $1.89 \mu \mathrm{M}$. The input data [fraction metabolized by an enzyme $\left(f_{\mathrm{m}}\right)$ values] for midazolam, repaglinide, and desipramine were 0.9 (Einolf et al., 2014), 0.71 (Kajosaari et al., 2005; Varma et al., 2013 ), and 0.9 (Obach et al., 2006), respectively. The input data ( $f_{\mathrm{m}}$ values) for other drugs were calculated from the published literature (Supplemental Table 2).

The $f_{\mathrm{mP} 450}$ value was calculated as follows:

$$
f_{\mathrm{m}}=\left[1-\left(1 / \mathrm{AUC}_{\mathrm{i}}\right)\right]
$$

where, $\mathrm{AUC}_{\mathrm{i}}$ represents the fold increase in the exposure of a substrate after coadministration with a strong inhibitor (Rowland and Matin, 1973). This equation assumes complete inhibition of the enzyme. The $F_{\mathrm{g}}$ values were not available for a majority of these substrates; a value of $0.51\left(F_{\mathrm{g}}\right.$ value of midazolam, which undergoes predominant gut metabolism) was used (Gertz et al., 2010).

\section{Selection of Drugs for AUCR Determination}

To predict the magnitude of CYP3A4/5-, CYP2C8-, and CYP2D6-mediated inhibition by clofazimine, the AUCR values were estimated using midazolam, repaglinide, and desipramine as probe substrates, respectively. Various classes of possible coadministered drugs such as antituberculars, antiretrovirals, antidiabetics, antihypertensives, antileprotics, and antihyperlipidemics (statins) were considered for further evaluation.

\section{PBPK Model Predictions}

Input Parameters. The platform used for the PBPK modeling was the Simcyp Simulator (version 15, release 1; Certara, Princeton, NJ). The healthy volunteer 
TABLE 1

PBPK model (Simcyp Simulator) input parameters for clofazimine

\begin{tabular}{|c|c|c|}
\hline Parameter & Value & Source \\
\hline \multicolumn{3}{|l|}{ Physicochemical properties } \\
\hline Molecular weight $(\mathrm{g} / \mathrm{mol})$ & 473 & \\
\hline $\log \mathrm{P}_{\text {o:w }}$ & 7.66 & ChemIDplus database \\
\hline $\mathrm{p} K_{\mathrm{a}}$ & 8.51 & Quigley et al. (1990) \\
\hline Compound type & Monoprotic base & \\
\hline $\mathrm{B} / \mathrm{P}$ & 0.55 & Internal data \\
\hline $\mathrm{fu}_{\mathrm{p}}$ & 0.001 & TB Alliance ${ }^{a}$ \\
\hline \multicolumn{3}{|l|}{ Absorption } \\
\hline Model & First-order absorption & \\
\hline$f_{\mathrm{a}}$ & $0.7(\mathrm{CV} 10 \%)$ & Vischer (1969) \\
\hline$k_{\mathrm{a}}\left(\mathrm{h}^{-1}\right)$ & 0.25 (CV 30\%) & Optimized to predict PK \\
\hline$T_{\text {lag }}(\mathrm{h})$ & $0.55(\mathrm{CV} 30 \%)$ & Optimized to predict PK \\
\hline$Q_{\text {gut }}(1 / \mathrm{h})$ & 12.7 & Predicted in Simcyp \\
\hline $\mathrm{fu}_{\text {gut }}$ & 0.001 & Assumption, same as $\mathrm{fu}_{\mathrm{p}}$ \\
\hline$P_{\text {eff,man }}\left(\times 10^{-4} \mathrm{~cm} / \mathrm{s}\right)$ & 4.38 & Predicted in GastroPlus \\
\hline \multicolumn{3}{|l|}{ Distribution } \\
\hline Model & Minimal PBPK model & \\
\hline$Q(1 / \mathrm{h})$ & 42.6 & Internal PopPK analysis \\
\hline$V_{\text {sac }}(1 / \mathrm{kg})$ & 32.7 & Internal PopPK analysis \\
\hline$V_{\mathrm{ss}}(1 / \mathrm{kg})$ & $47.5(\mathrm{CV} 20 \%)$ & Internal PopPK analysis \\
\hline \multicolumn{3}{|l|}{ Elimination } \\
\hline $\mathrm{CL}_{\mathrm{iv}}(\mathrm{l} / \mathrm{h})$ & 4.18 (CV 30\%) & Internal PopPK analysis \\
\hline $\mathrm{CL}_{\mathrm{R}}(\mathrm{l} / \mathrm{h})$ & 0 & Levy (1974) \\
\hline \multicolumn{3}{|l|}{ Interaction } \\
\hline \multicolumn{3}{|l|}{ Reversible inhibition } \\
\hline CYP3A4 $K_{\mathrm{i}, \mathrm{u}}(\mu \mathrm{M})$ & 0.000786 & Measured $^{b}$ \\
\hline CYP2C8 $K_{\mathrm{i}, \mathrm{u}}(\mu \mathrm{M})$ & 0.00372 & Measured $^{b}$ \\
\hline CYP2D6 $K_{\mathrm{i}, \mathrm{u}}(\mu \mathrm{M})$ & 0.00246 & Measured $^{b}$ \\
\hline
\end{tabular}

$\mathrm{B} / \mathrm{P}$, blood-to-plasma ratio; $\mathrm{CL}_{\mathrm{iv}}$, in vivo intravenous clearance; $\mathrm{CL}_{\mathrm{R}}$, renal clearance; fu $\mathrm{gu}_{\text {gut }}$, fraction unbound in the enterocyte; $\log \mathrm{P}_{\mathrm{o}: \mathrm{w}}$ logarithmic partition coefficient octonal:water; $P_{\text {eff,man }}$, effective permeability in man; $Q$, inter-compartment clearance; $T_{\text {lag, }}$ lag time; $V_{\text {sac }}$ single adjusted compartment volume; $V_{\mathrm{ss}}$, volume of distribution at steady state.

${ }^{a}$ Global Alliance for TB Drug Development (http://www.resisttb.org/wp-content/uploads/2013/08/Global-Alliance-Clinical-Work-withClofazimine.pdf).

${ }^{b}$ Supplemental Table 1.

population library file provided by the software was used for all simulations. For simulations that included patients up to 70 years of age, the default maximum age for the healthy volunteer population file was increased from 65 to 70 . The PBPK model input parameters are summarized in Table 1 and described in detail subsequently.

The molecular weight of clofazimine is $473 \mathrm{~g} / \mathrm{mol}$, and the $\log \mathrm{P}$ octanol:water value used was 7.66 (ChemIDplus database; U.S. National Library of Medicine, Bethesda, MD, https://chem.nlm.nih.gov/chemidplus/). The compound type was entered as a monoprotic base with an acid dissociation constant $\mathrm{p} K_{\mathrm{a}}$ value of 8.51 (Quigley et al., 1990). The blood-to-plasma ratio was entered as 0.5 (minimally distributed into blood; internal data), and the $\mathrm{fu}_{\mathrm{p}}$ was entered as 0.001 (http:// www.resisttb.org/wp-content/uploads/2013/08/Global-Alliance-Clinical-Workwith-Clofazimine.pdf). A first-order absorption model was used and the fraction of dose absorbed $\left(f_{\mathrm{a}}\right)$ was entered as 0.7 (Vischer, 1969). A parameter sensitivity analysis was performed on the impact of the clofazamine $f_{\mathrm{a}}$ value on the drug interaction with the sensitive CYP3A4 substrate, midazolam (Supplemental Fig. 1A). Varying the $f_{\mathrm{a}}$ value from 0.42 to $0.98(0.7 \% \pm 40 \%$ of the value used in the model) resulted in a predicted midazolam AUCR range of 2.2-3.7, which was within $38 \%$ of the predicted AUCR of 2.7 with a $f_{\mathrm{a}}$ value of 0.7 . The results of this parameter sensitivity analysis suggested that the CYP3A drug-drug interaction (DDI) was not highly sensitive to the clofazimine $f_{\mathrm{a}}$ values evaluated and would remain categorized as a moderate CYP3A4 inhibitor. The absorption rate constant $\left(k_{\mathrm{a}}\right)$ used was 0.25 hour $^{-1}$ and the lag time was entered as 0.55 hour. These values were optimized to predict the pharmacokinetics (PK) parameters (e.g., the $C_{\max }$ and time to reach maximum plasma concentration values). The effective permeability in humans was user defined as $4.38 \times 10^{-4} \mathrm{~cm} / \mathrm{s}$, predicted based

TABLE 2

Summary of clofazimine PK simulations

The elimination half-life of clofazimine is approximately 25 days, thus it is assumed that the exposure clofazimine reaches steady state in plasma by day 126 (approximately five half-lives).

\begin{tabular}{|c|c|c|c|c|}
\hline Study (Model) & $\begin{array}{l}\text { Clofazimine Dosing } \\
\text { Regimen }\end{array}$ & Simulated Population & Observed Population & PK Measurement of Substrate \\
\hline \multicolumn{5}{|l|}{ Model development } \\
\hline $\begin{array}{l}\text { Clofazimine PK } \\
\text { (Internal data) }\end{array}$ & $\begin{array}{l}50 \mathrm{mg} \text { once daily for } \\
43 \text { days (fasting) }\end{array}$ & $\begin{array}{l}\text { Age range: } 35-64 \text { years; proportion } \\
\text { of females: } 25 \% n=120 \text { (10 trials } \\
\text { of } 12 \text { subjects })\end{array}$ & $\begin{array}{l}\text { Age range: } 35-64 \text { years; proportion } \\
\text { of females: } 25 \% n=12\end{array}$ & Day 1: $T_{\max }, C_{\max }$, and $\mathrm{AUC}_{0-24 \mathrm{~h}}$ \\
\hline $\begin{array}{l}\text { Clofazimine PK } \\
\text { (Internal data) }\end{array}$ & $\begin{array}{l}100 \mathrm{mg} \text { once daily for } \\
43 \text { days (fasting) }\end{array}$ & $\begin{array}{l}\text { Age range: } 45-70 \text { years; proportion } \\
\text { of females: } 50 \% n=120 \text { (10 trials } \\
\text { of } 12 \text { subjects })\end{array}$ & $\begin{array}{l}\text { Age range: } 45-76 \text { years; proportion } \\
\text { of females: } 50 \% n=12\end{array}$ & Day 1: $T_{\max }, C_{\max }$, and $\mathrm{AUC}_{0-24 \mathrm{~h}}$ \\
\hline \multicolumn{5}{|l|}{ Model application } \\
\hline Clofazimine PK & $\begin{array}{l}100 \mathrm{mg} \text { once daily for } \\
126 \text { days (fasting) }\end{array}$ & $\begin{array}{l}\text { Age range: } 18-70 \text { years; proportion } \\
\text { of females: } 50 \% n=100(10 \text { trials } \\
\text { of } 10 \text { subjects })\end{array}$ & NA & Day 126: $C_{\max }$ and $\mathrm{AUC}_{0-24 \mathrm{~h}}$ \\
\hline
\end{tabular}


TABLE 3

DDI predictions of clofazimine with P450 substrates

\begin{tabular}{|c|c|c|c|}
\hline Model Application (P450 Substrate) & Study & Dosing Regimen & PK Measurement of Substrate \\
\hline CYP3A4/5 & Midazolam + clofazimine & $\begin{array}{l}\text { Midazolam } 5 \mathrm{mg} \text { on day } 126+\text { clofazimine } 100 \mathrm{mg} \\
\text { once daily on days } 1-126\end{array}$ & Day 126: $\mathrm{AUC}_{\mathrm{inf}}, C_{\max }$ \\
\hline CYP3A4 & Saquinavir + clofazimine & $\begin{array}{l}\text { Saquinavir } 1200 \mathrm{mg} \text { on day } 126+\text { clofazimine } 100 \mathrm{mg} \\
\text { once daily on days } 1-126\end{array}$ & Day 126: $\mathrm{AUC}_{\mathrm{inf}}, C_{\max }$ \\
\hline CYP3A4 & Efavirenz + clofazimine & $\begin{array}{l}\text { Efavirenz } 600 \mathrm{mg} \text { on day } 126+\text { clofazimine } 100 \mathrm{mg} \\
\text { once daily on days } 1-126\end{array}$ & Day 126: $\mathrm{AUC}_{\mathrm{inf}}, C_{\max }$ \\
\hline CYP2C8 & Repaglinide + clofazimine & $\begin{array}{l}\text { Repagalinide } 0.25 \mathrm{mg} \text { on day } 126+\text { clofazimine } 100 \mathrm{mg} \\
\text { once daily on days } 1-126\end{array}$ & \\
\hline CYP2D6 & Desipramine + clofazimine & $\begin{array}{l}\text { Desipramine } 50 \mathrm{mg} \text { on day } 126+\text { clofazimine } 100 \mathrm{mg} \\
\text { once daily on days } 1-126\end{array}$ & \\
\hline
\end{tabular}

$\mathrm{AUC}_{\mathrm{inf}}$, area under the plasma concentration-time curve from 0 to infinity.

on the clofazimine chemical structure by using the absorption, distribution, metabolism, excretion, and toxicity predictor in GastroPlus (Simulations Plus, Inc., Lancaster, CA). The $Q_{\text {gut }}$ value was predicted as $12.7 \mathrm{l} / \mathrm{h}$ by the Simcyp Simulator. The fraction unbound in the enterocyte value was set at 0.001 (assumed to be the same as $\mathrm{fu}_{\mathrm{p}}$ ). The coefficient of variation $(30 \%)$ for the input parameters was the default value in the Simcyp Simulator. In addition, sensitivity analyses of the clofazimine fraction unbound in the enterocyte as well as the $k_{\mathrm{a}}$ value were performed to determine the impact of these values on the drug interaction with midazolam. The results of the sensitivity analysis can be found in Supplemental Fig. 1, B and C. Variation of the fraction unbound in the enterocyte (range of 0.001-1) resulted in minimal impact in the midazolam AUCR (range of 3.0-3.9) and categorization of the DDI. The predicted DDI of clofazimine with midazolam was not sensitive to $k_{\mathrm{a}}$ values ranging from 0.088 to 0.25 hour $^{-1}$ (i.e., values used in either the static or PBPK models). The minimal PBPK model in the Simcyp Simulator was used with a single adjusting compartment. The input parameters for distribution were optimized to best fit the PK data obtained from the clinical trial (PopPK analysis, internal data); the volume of distribution at steady state, intercompartment clearance $(Q)$, and single adjusted compartment volume were estimated to be $47.5 \mathrm{l} / \mathrm{kg}, 42.6 \mathrm{l} / \mathrm{h}$, and $32.71 / \mathrm{kg}$, respectively. The in vivo intravenous clearance was user defined as $4.18 \mathrm{l} / \mathrm{h}$, also optimized to best fit of the PK data from the clinical trial. Renal clearance of clofazimine was deemed to be negligible since less than $1 \%$ of the administered drug was reported to be eliminated in the urine (Levy 1974). The inhibition parameters entered in the Simcyp Simulator were already corrected for microsomal protein binding (Supplemental Table 3).

\section{Model Performance and Application}

PK Trial Simulations. The PK parameter inputs for the simulations were estimated using the clinical PK data of clofazimine. The simulated data were qualified using the observed PK data from the same study (Table 2).

DDI Predictions of Clofazimine as a Perpetrator of P450 Substrates. For DDI simulations using PBPK modeling, midazolam and selected antivirals such as saquinavir or efavirenz were considered as CYP3A4/5 substrates. Repaglinide and desipramine were used as CYP2C8 and CYP2D6 substrates, respectively. The Supplemental Material contains details of the input parameters for the substrates used in the PBPK model (Supplemental Tables 4-8). A total of 10 trials including 10 subjects were simulated; the age range of the simulated subjects was 18-70 years, with $50 \%$ of the population being women (Table 3 ).

\section{Results}

\section{Static Model Predictions}

$R_{1}$ Values for CYP3A4/5 Inhibition. The $R_{1}$ values for P450 inhibition by clofazimine are listed in Table 4 . Since the calculated $R_{1}$ values of clofazimine were $>1.1$ for both total and unbound maximum anticipated $C_{\max }$ (inhibitor concentration) and $>11$ for $\left[\mathrm{I}_{\text {gut }}\right]$, the AUCR was determined using the mechanistic static (net effect) model and by incorporating estimated $f_{\mathrm{m}}$ and $F_{\mathrm{g}}$ values of the interacting substrates.

\section{AUCR Values for Clofazimine with Sensitive Substrates}

The AUCR values were determined to estimate the extent of risk with respect to $\mathrm{P} 450$ inhibition in vivo when clofazimine was coadministered with $\mathrm{P} 450$ substrates. The AUCR values of midazolam, repaglinide, and desipramine with clofazimine were estimated as 5.59, 1.34, and 1.69, respectively. Based on these calculated net effect values, clofazimine was predicted to be a strong CYP3A4/5 inhibitor and a weak CYP2C8 and CYP2D6 inhibitor in vivo.

Predicted AUCR for Inhibition of CYP3A4/5-Mediated Clearance. For the selected substrates evaluated, approximately 2- to 6-fold increase in the AUC was predicted when coadministered once daily with $100 \mathrm{mg}$ clofazimine (Table 5).

\section{PBPK Model Predictions}

Simulations of Clofazimine PK on Days 1 and 126. The predicted the AUC, $C_{\max }$, and time to reach maximum plasma concentration values on day 1 using the PBPK model were within 2-fold of the observed values. The observed and simulated clinical PK parameters on day 1 for clofazimine following single oral doses $(50$ and $100 \mathrm{mg}$ ) are summarized in Table 6 . The simulated clinical PK parameters for clofazimine at day 126 following multiple oral doses of $100 \mathrm{mg}$ once daily can be found in Table 7 . The predicted $C_{\max }$ value $(797 \mathrm{ng} / \mathrm{ml})$ on day 126 after multiple doses was comparable to the $C_{\max }$ value $(890 \mathrm{ng} / \mathrm{ml})$ predicted from the PopPK model, which was used for the static model.

DDI Simulations of CYP3A (Midazolam, Saquinavir, and Efavirenz), CYP2C8 (Repaglinide), and CYP2D6 (Desipramine) Substrates with Clofazimine. The predicted AUC and $C_{\max }$ ratios for midazolam with clofazimine were predicted as 2.69 and 1.68, respectively. The predicted AUC and $C_{\max }$ ratios of saquinavir when

TABLE 4

Input parameters and $R_{1}$ values for $\mathrm{P} 450$ inhibition by clofazimine

\begin{tabular}{llcc}
\hline & \multicolumn{3}{c}{ P450 Enzyme } \\
\cline { 2 - 4 } Input Parameter $/ R_{1}$ Value & CYP3A4/5 & CYP2C8 & CYP2D6 \\
\hline Input parameter & & & \\
$K_{\mathrm{i}, \mathrm{u}}(\mu \mathrm{M})$ & 0.000786 & 0.00372 & 0.00246 \\
{$[\mathrm{I}](\mu \mathrm{M}) ;$ total $C_{\max }$} & $1.89^{a}$ & $1.89^{a}$ & $1.89^{a}$ \\
{$[\mathrm{I}](\mu \mathrm{M}) ;$ unbound $C_{\max }$} & 0.00189 & 0.00189 & 0.00189 \\
{$\left[\mathrm{I}_{\text {gut }}(\mu \mathrm{M}) ;\right.$ total } & 845 & $-b$ & - \\
$R_{1}$ Value & & & \\
Systemic: $[\mathrm{I}]=C_{\max , \text { total }}$ & 2406 & 509 & 769 \\
Systemic: $[\mathrm{I}]=C_{\max , \mathrm{u}}$ & 3.40 & 2 & 2 \\
Gut: $[\mathrm{I}]=\left[\mathrm{I}_{\text {gut }}\right]$ & $1,075,065$ & - & - \\
\hline
\end{tabular}

[I], inhibitor concentration (maximum anticipated $C_{\max }$ ).

${ }^{a}$ Predicted concentration after repeat administration of $100 \mathrm{mg} /$ day clofazimine.

${ }_{b}$, not applicable. 
TABLE 5

Predicted fold change in the AUC of selected substrates of CYP3A4/5

For the weak CYP3A4/5 inhibitor the AUCRs are $>1.25$ and $<2$. For the moderate CYP3A4/5 inhibitor the AUCRs are $>2$ and $<5$. For the strong CYP3A4/5 inhibitor the AUCR is $\geq 5$.

\begin{tabular}{|c|c|}
\hline Class/Substrate & Predicted AUCR \\
\hline \multicolumn{2}{|l|}{ Antiretrovirals } \\
\hline Atazanavir & 2.10 \\
\hline Amprenavir & 2.39 \\
\hline Darunavir & 2.50 \\
\hline Delaviridine & 2.57 \\
\hline Dolutegravir & 3.00 \\
\hline Efavirenz & 2.48 \\
\hline Elvitegravir & 2.62 \\
\hline Etravirine & 2.57 \\
\hline Indinavir & 4.48 \\
\hline Lopinavir & 2.52 \\
\hline Nelfinavir & 2.41 \\
\hline Raltegravir & 2.81 \\
\hline Ritonavir & 2.57 \\
\hline Rilpivirine & 2.57 \\
\hline Saquinavir & 2.96 \\
\hline Simeprevir & 5.16 \\
\hline Tipranavir & 5.83 \\
\hline \multicolumn{2}{|l|}{ Antituberculars } \\
\hline Bedaquiline & 2.25 \\
\hline Clarithromycin & 2.93 \\
\hline Delamanid & 5.59 \\
\hline \multicolumn{2}{|l|}{ Antihypertensives } \\
\hline Losartan & 2.35 \\
\hline Verapamil & 2.50 \\
\hline Diltiazem & 2.62 \\
\hline Nitrendipine & 3.37 \\
\hline Amlodipine & 3.79 \\
\hline Guanfacine & 3.79 \\
\hline Nifedipine & 3.85 \\
\hline Eplerenone & 4.72 \\
\hline Felodipine & 4.88 \\
\hline Lercanidipine & 5.96 \\
\hline \multicolumn{2}{|l|}{ Antidiabetics } \\
\hline Alogliptin & 2.23 \\
\hline Pioglitazone & 2.39 \\
\hline Repaglinide & 2.48 \\
\hline Teneligliptin & 2.57 \\
\hline Saxagliptin & 3.46 \\
\hline \multicolumn{2}{|l|}{ Antihyperlipidemics } \\
\hline Pravastatin & 2.90 \\
\hline Atorvastatin & 4.88 \\
\hline Simvastatin & 5.83 \\
\hline Lovastatin & 6.23 \\
\hline \multicolumn{2}{|l|}{ Antileprotics } \\
\hline Dapsone & 1.97 \\
\hline
\end{tabular}

coadministered with clofazimine were predicted to be 2.89- and 2.42-fold, respectively. No change in the AUC or $C_{\max }$ ratios was predicted by the PBPK model for efavirenz in the presence of clofazimine. In addition, the predicted AUCRs for repaglidine (CYP2C8 substrate) and desipramine (CYP2D6 substrate) with clofazimine were 1.60 and 1.47 , respectively (Table 8).

\section{Discussion}

Clofazimine is currently being considered as a core second-line drug for treatment of DR-TB (see the WHO treatment guidelines; http://www.who.int/tb/areas-of-work/drug-resistant-tb/treatment/en/). As per the WHO TB treatment guidelines, clofazimine is administered as part of a multidrug regimen; therefore, evaluating the drug interaction potential of clofazimine will be beneficial to arrive at appropriate dosing regimens for the coadministered drugs. In the absence of clinical drug interaction studies, data derived from in vitro experiments and modeling were used to predict the drug interaction potential of clofazimine.
TABLE 6

Observed and simulated clinical PK parameters for clofazimine in patients following single oral doses (50 and $100 \mathrm{mg}$ )

\begin{tabular}{ccc}
\hline & \multicolumn{2}{c}{ Clofazimine (Mean \pm S.D.) } \\
\cline { 2 - 3 } Parameter & Oral Dose $(50 \mathrm{mg})$ & Oral Dose $(100 \mathrm{mg})$ \\
\hline$C_{\text {max }}(\mathrm{ng} / \mathrm{ml})$ & $71.8 \pm 34.1$ & $131 \pm 59.9$ \\
Observed $^{a}$ & $83.3 \pm 219$ & $178 \pm 465$ \\
Predicted $_{\text {PE }(\%)^{b}}$ & $+16 \%$ & $+36 \%$ \\
AUC $_{0-24 \mathrm{~h}}(\mathrm{ng} \cdot \mathrm{h} / \mathrm{ml})$ & $1084 \pm 409$ & $1856 \pm 821$ \\
Observed $^{a}$ & $976 \pm 1633$ & $2090 \pm 3691$ \\
Predicted $_{\text {PE }(\%)^{b}}$ & $-10 \%$ & $+13 \%$ \\
$T_{\text {max }}(\mathrm{h})^{c}$ & 8 & 6 \\
Observed & & \\
Predicted & 9.5 & 9.5 \\
PE $(\%)^{b}$ & $+19 \%$ & $+58 \%$ \\
\hline
\end{tabular}

$\mathrm{AUC}_{0-24 \mathrm{~h}}$, area under plasma-drug concentration curve between 0 and 24 hours; PE, prediction error $(\%) ; T_{\max }$, time to reach maximum concentration.

${ }^{a}$ Clinical PK parameters were not available on day 43 ; hence, the day 1 PK parameters were used for comparison; picomoles per grams was converted to nanograms per milliliter as follows: $\mathrm{pmol} / \mathrm{g}=(\mathrm{pmol} / \mathrm{g}) \times$ molecular weight $(\mathrm{g} / \mathrm{mol})=\mathrm{pmol} / \mathrm{mol}=\mathrm{ng} / \mathrm{g}=\mathrm{ng} / \mathrm{ml}$, where plasma density assumes a value of $\sim 1 \mathrm{~g} / \mathrm{ml}$.

${ }^{b}$ Prediction error $=[$ (predicted value - observed value $) /$ observed value $] \times 100$.

${ }^{c}$ Median.

In the static model, the clofazimine $R_{1}$ values for CYP3A4/5, CYP2C8, and CYP2D6 were found to be $>1.1$ and $>11$ for systemic inhibitor concentration and $\left[\mathrm{I}_{\text {gut }}\right]$, respectively. Therefore, the possibility of a P450 inhibition-mediated interaction for clofazimine cannot be ruled out (https:// www.fda.gov/downloads/drugs/guidances/ucm292362.pdf). The DDI potential was further evaluated by the mechanistic static (net effect) model, where the AUCR was determined using the probe substrates (midazolam, repaglinide, and desipramine for CYP3A4/5, CYP2C8, and CYP2D6, respectively). $\mathrm{P} 450$ inhibitors are typically classified as strong, moderate, or weak based on the magnitude of changes in the plasma AUC of the probe substrates: $\geq 5$-fold, strong inhibitor; between 2- and 5-fold, moderate inhibitor; and between 1.25- and 2-fold, weak inhibitor (https://www.fda. gov/downloads/drugs/guidances/ucm292362.pdf). The estimated AUCR values of clofazimine are 5.59, 1.34, and 1.69 for midazolam (CYP3A4/5), repaglinide (CYP2C8), and desipramine (CYP2D6), respectively. Similar results were obtained for clofazimine when the DDI was simulated using a PBPK model for repaglinide and desipramine. Thus, clofazimine can be classified as a weak inhibitor of CYP2C8 and CYP2D6.

The fold increase in exposure predicted using the PBPK model (AUCR of 2.69) was approximately 50\% lower than that calculated using the mechanistic static (net effect) model (AUCR of 5.59) for midazolam. No change in the AUC or $C_{\max }$ value was predicted by the PBPK model for efavirenz in the presence of clofazimine; however, the static model predicted a 2.48-fold increase in the AUC. Considering the fold increase in the AUC predicted using both models, clofazimine can be classified as a moderate-to-strong inhibitor of CYP3A4/5.

The findings from the drug interaction predictions were further qualified against the available clinical evidence in Balakrishnan and Seshadri (1981), where clofazimine was coadministered with dapsone (a CYP3A4 substrate). The study concluded that there was no significant effect on the exposure of dapsone when administered with clofazimine (Balakrishnan and Seshadri, 1981). The AUCR value for dapsone with clofazimine was estimated to be 1.97 and predicted weak inhibition by clofazimine on dapsone PK. This is in agreement with the clinical data where no interaction was observed. The minimal difference between the findings from the predicted and observed value can be attributed to the fact that dapsone is also metabolized by CYP2C9 (Gill et al., 1995). 
TABLE 7

Simulated clinical PK parameters for clofazimine on day 126 following multiple oral doses of $100 \mathrm{mg}$ once daily

An example of the summary model input, output, and PK statistical output for this scenario can be found in the Supplemental Tables 9-11.

\begin{tabular}{lc}
\hline \multicolumn{1}{c}{ Parameter } & Value \\
\hline Mean $C_{\max }(\mathrm{ng} / \mathrm{ml})$ & 797 (S.D.: 392) \\
Mean $\mathrm{AUC}_{0-24 \mathrm{~h}}(\mathrm{ng} \cdot \mathrm{h} / \mathrm{ml})$ & 16,627 (S.D.: 5367) \\
Median $C_{\max }(\mathrm{ng} / \mathrm{ml})$ & $703($ minimum: 255; maximum: 2966) \\
Median $\mathrm{AUC} C_{0-24}(\mathrm{ng} \cdot \mathrm{h} / \mathrm{ml})$ & $15,919($ minimum: 5868; maximum: 36,902) \\
Geometric mean $C_{\max }(\mathrm{ng} / \mathrm{ml})$ & $728(\mathrm{CV} \%: 49)$ \\
Geometric mean $\mathrm{AUC}$ & $15,797(\mathrm{CV} \%: 32)$ \\
\hline
\end{tabular}

$\mathrm{AUC}_{0-24 \mathrm{~h}}$, area under plasma-drug concentration curve between 0 and 24 hours.

In view of the most frequent comorbidities associated with TB and the multidrug regimen used for DR-TB treatment, various classes of antituberculars, antiretrovirals, antidiabetics, antihypertensives, antileprotics, and antihyperlipidemics (statins) that undergo metabolism by CYP3A4/5 were considered for AUCR evaluation. Clofazimine is always administered as part of a multidrug regimen, either as a shorter or conventional regimen (WHO guidelines; http://www.who.int/tb/areasof-work/drug-resistant-tb/treatment/en/). The shorter regimen contains kanamycin (an injectable agent), moxifloxacin, prothionamide, clofazimine, isoniazid, pyrazinamide, and ethambutol, given together in an initial phase of 4 months, and followed by 5 months of treatment with four of the medicines (moxifloxacin, clofazimine, pyrazinamide, and ethambutol). For the conventional regimen, the intensive phase includes pyrazinamide and four second-line drugs (fluoroquinolones: levofloxacin, moxifloxacin, and gatifloxacin; second-line injectables: amikacin, capreomycin, kanamycin, and streptomycin; and core second-line agents: ethionamide/ prothionamide, cycloserine/terizidone, linezolid, and clofazimine). If the minimum of effective TB medicines cannot be composed, either a group D2 drug (bedaquiline or delamanid), and possibly group D3 agents ( $p$-aminosalicylic acid, imipenem-cilastatin, meropenem, amoxicillin-clavulanate, or thioacetazone) could be added. With the exception of bedaquiline and delaminid, no P450-mediated interaction was predicted for other antitubercular drugs (fluroquinolones, second-line injectables, core second-line agents, and D1 and D3 agents) that are currently recommended by WHO for treatment of DR-TB (both shorter and conventional regimens).

For most of the tested antiretroviral drugs known to be metabolized by CYP3A4/5, moderate interactions were assessed, with an estimation of between 2- and 5-fold increase in the AUC of the antiretroviral drug [except simeprevir (5.13-fold) and tipranavir (5.83-fold)] when administered concomitantly with clofazimine $100 \mathrm{mg} /$ daily. Moderate inhibitions were predicted for some of the dipeptidyl peptidase- 4 inhibitors tested. Moderate-to-strong inhibitions were predicted for antihypertensives and antihyperlipidemic drugs (pravastatin, atorvastatin, simvastatin, and lovastatin) when administered concomitantly with clofazimine $100 \mathrm{mg} / \mathrm{d}$.

In conclusion, clofazimine was predicted to be a weak CYP2C8 and CYP2D6 inhibitor. Thus, the possibility of a clinically significant interaction when coadministered with CYP2C8 and CYP2D6 substrate is minimal. Clofazimine is predicted to be a moderate-tostrongCYP3A4/5 inhibitor based on the net effect and PBPK modeling predictions. In the absence of a clinical DDI study, the possibility of an increase in the AUC of CYP3A4/5 substrates when coadministered with clofazimine cannot be ignored. Thus, caution is recommended when clofazimine is prescribed along with a CYP3A4/5 substrate.

\section{Acknowledgments}

We acknowledge V.S. Muthuswamy (Novartis Healthcare Pvt. Ltd., Hyderabad, India) for the literature review support in this study. We thank Jitendriya Mishra (Novartis Healthcare Pvt. Ltd., Hyderabad, India) for providing medical writing assistance of this manuscript.

\section{Authorship Contributions}

Participated in research design: Sangana, Gu, Chun, Einolf.

Conducted experiments: Sangana, Gu, Chun.

Performed data analysis: Sangana, Gu, Einolf.

Wrote or contributed to the writing of the manuscript: Sangana, Gu, Chun, Einolf.

TABLE 8

Predicted clinical PK parameters in plasma for midazolam, saquinavir, efavirenz, repaglinide, and desipramine Single dose given on day 126 in the presence and absence of clofazimine (100 $\mathrm{mg}$ once daily, days 1-126).

\begin{tabular}{|c|c|c|c|c|c|c|}
\hline \multirow{3}{*}{ Substrate (dose) Simulated $n=100$} & \multicolumn{2}{|c|}{ Mean (S.D.) } & \multicolumn{2}{|c|}{ Geometric Mean (CV\%) } & \multicolumn{2}{|c|}{ Geometric Mean Ratio $(90 \% \mathrm{CI})$} \\
\hline & $\mathrm{AUC}_{\mathrm{inf}}$ & $C_{\max }$ & $\mathrm{AUC}_{\mathrm{inf}}$ & $C_{\max }$ & \multirow{2}{*}{ AUC } & \multirow{2}{*}{$C_{\max }$} \\
\hline & $n g / m l \cdot h$ & $n g / m l$ & $n g / m l \cdot h$ & $n g / m l$ & & \\
\hline Midazolam (5 mg) & $72.1(55.8)$ & $25.1(16.9)$ & $56.0(77)$ & $20.4(68)$ & & \\
\hline Midazolam (5 mg) + clofazimine & $214(174)$ & $42.3(27.0)$ & $151(81)$ & $34.2(64)$ & $2.69(2.58,2.80)$ & $1.68(1.62,1.74)$ \\
\hline Saquinavir $(1200 \mathrm{mg})$ & 2197 (1519) & $388(309)$ & $1810(69)$ & $304(80)$ & & \\
\hline Saquinavir $(1200 \mathrm{mg})+$ clofazimine & $6164(3730)$ & $886(567)$ & $5224(60)$ & $736(64)$ & $2.89(2.87,2.90)$ & $2.42(2.30,2.53)$ \\
\hline Efavirenz $(600 \mathrm{mg})$ & $118,424(78,432)$ & 2376 (1653) & $97,306(66)$ & $1950(70)$ & & \\
\hline Efavirenz $(600 \mathrm{mg})+$ clofazimine & $124,951(86,932)$ & $2389(1671)$ & $101,211(64)$ & $1958(70)$ & $1.04(1.04,1.04)$ & $1.00(1.00,1.00)$ \\
\hline Repaglinide $(0.25 \mathrm{mg})$ & $8.27(4.16)$ & $3.83(1.36)$ & $7.14(50)$ & $3.56(36)$ & & \\
\hline Repaglinide $(0.25 \mathrm{mg})+$ clofazimine & $13.6(8.75)$ & $5.04(1.78)$ & $11.4(59)$ & $4.69(35)$ & $1.60(1.58,1.76)$ & $1.32(1.29,1.34)$ \\
\hline Desipramine $(50 \mathrm{mg})$ & $2836(7808)$ & $17.3(11.4)$ & $688(275)$ & $14.5(66)$ & & \\
\hline Desipramine $(50 \mathrm{mg})+$ clofazimine & 3125 (7745) & $20.4(11.6)$ & 1009 (248) & $17.7(57)$ & $1.47(1.44,1.50)$ & $1.27(1.24,1.30)$ \\
\hline
\end{tabular}

$\mathrm{AUC}_{\text {inf }}$, area under plasma-drug concentration curve from 0 to infinity; CI, confidence interval. 


\section{References}

Aung KJ, Van Deun A, Declercq E, Sarker MR, Das PK, Hossain MA, and Rieder HL (2014) Successful '9-month Bangladesh regimen' for multidrug-resistant tuberculosis among over 500 consecutive patients. Int J Tuberc Lung Dis 18:1180-1187.

Balakrishnan S and Seshadri PS (1981) Drug interactions-the influence of rifampicin and clofazimine on the urinary excretion of DDS. Lepr India 53:17-22.

Dooley KE, Obuku EA, Durakovic N, Belitsky V, Mitnick C, and Nuermberger EL; Efficacy Subgroup, RESIST-TB (2013) World Health Organization group 5 drugs for the treatment of drug-resistant tuberculosis: unclear efficacy or untapped potential? J Infect Dis 207:1352-1358.

Einolf HJ, Chen L, Fahmi OA, Gibson CR, Obach RS, Shebley M, Silva J, Sinz MW, Unadkat JD, Zhang L, et al. (2014) Evaluation of various static and dynamic modeling methods to predict clinical CYP3A induction using in vitro CYP3A4 mRNA induction data. Clin Pharmacol Ther 95:179-188.

Fahmi OA, Hurst S, Plowchalk D, Cook J, Guo F, Youdim K, Dickins M, Phipps A, Darekar A, Hyland R, et al. (2009) Comparison of different algorithms for predicting clinical drug-drug interactions, based on the use of CYP3A4 in vitro data: predictions of compounds as precipitants of interaction. Drug Metab Dispos 37:1658-1666.

Fahmi OA, Maurer TS, Kish M, Cardenas E, Boldt S, and Nettleton D (2008) A combined model for predicting CYP3A4 clinical net drug-drug interaction based on CYP3A4 inhibition, inactivation, and induction determined in vitro. Drug Metab Dispos 36: $1698-1708$

Fajardo TT, Abalos RM, dela Cruz EC, Villahermosa LG, Walsh DS, Cellona RV, Balagon MV, Tan EV, and Walsh GP (1999) Clofazimine therapy for lepromatous leprosy: a historical perspective. Int $J$ Dermatol 38:70-74.

Gertz M, Harrison A, Houston JB, and Galetin A (2010) Prediction of human intestinal first-pass metabolism of 25 CYP3A substrates from in vitro clearance and permeability data. Drug Metab Dispos 38:1147-1158.

Gill HJ, Tingle MD, and Park BK (1995) $N$-Hydroxylation of dapsone by multiple enzymes of cytochrome P450: implications for inhibition of haemotoxicity. Br J Clin Pharmacol 40:531-538.

Horita Y and Doi N (2014) Comparative study of the effects of antituberculosis drugs and antiretroviral drugs on cytochrome P450 3A4 and p-glycoprotein. Antimicrob Agents Chemother 58: $3168-3176$.

Hwang TJ, Dotsenko S, Jafarov A, Weyer K, Falzon D, Lunte K, Nunn P, Jaramillo E, Keshavjee S, and Wares DF (2014) Safety and availability of clofazimine in the treatment of multidrug and extensively drug-resistant tuberculosis: analysis of published guidance and meta-analysis of cohort studies. BMJ Open 4:e004143.

Kajosaari LI, Laitila J, Neuvonen PJ, and Backman JT (2005) Metabolism of repaglinide by CYP2C8 and CYP3A4 in vitro: effect of fibrates and rifampicin. Basic Clin Pharmacol Toxicol 97:249-256.

Kuaban C, Noeske J, Rieder HL, Ait-Khaled N, Abena Foe JL, and Trébucq A (2015) High effectiveness of a 12-month regimen for MDR-TB patients in Cameroon. Int J Tuberc Lung Dis 19:517-524.

Levy L (1974) Pharmacologic studies of clofazimine. Am J Trop Med Hyg 23:1097-1109.

Obach RS, Walsky RL, Venkatakrishnan K, Gaman EA, Houston JB, and Tremaine LM (2006) The utility of in vitro cytochrome $\mathrm{P} 450$ inhibition data in the prediction of drug-drug interactions. J Pharmacol Exp Ther 316:336-348.

Piubello A, Harouna SH, Souleymane MB, Boukary I, Morou S, Daouda M, Hanki Y, and Van Deun A (2014) High cure rate with standardised short-course multidrug-resistant tuberculosis treatment in Niger: no relapses. Int J Tuberc Lung Dis 18:1188-1194.

Quigley JM, Fahelelbom KMS, Timoney RF, and Corrigan OI (1990) Temperature dependence and thermodynamics of partitioning of clofazimine analogues in the $n$-octanol/water system. Int J Pharm 58:107-113.

Rowland M and Matin SB (1973) Kinetics of drug-drug interactions. J Pharmacokinet Biopharm 1:553-567.

Van Deun A, Maug AK, Salim MA, Das PK, Sarker MR, Daru P, and Rieder HL (2010) Short, highly effective, and inexpensive standardized treatment of multidrug-resistant tuberculosis Am J Respir Crit Care Med 182:684-692.

Varma MV, Lai Y, Kimoto E, Goosen TC, El-Kattan AF, and Kumar V (2013) Mechanistic modeling to predict the transporter- and enzyme-mediated drug-drug interactions of repaglinide. Pharm Res 30:1188-1199.

Vischer WA (1969) The experimental properties of G 30320 (B 663)-a new anti-leprotic agent. Lepr Rev 40:107-110.

Zumla A, Raviglione M, Hafner R, and von Reyn CF (2013) Tuberculosis. N Engl J Med 368 $745-755$.

Address correspondence to: Dr. Heidi J. Einolf, Novartis Pharmaceuticals Corporation, East Hanover, NJ 07936. E-mail: heidi.einolf@novartis.com 